Polít. crim. Vol. 14, No 27 (Julio 2019), Art. 4, pp. 98-121

[http://politcrim.com/wp-content/uploads/2019/06/Vol14N27A4.pdf]

\title{
El recurso excesivo al Derecho penal en España. Realidad y alternativas*
}

\section{The excessive use of Criminal Law in Spain. Reality and alternatives}

\author{
Deborah García Magna \\ Profesora de Derecho penal y Criminología \\ Universidad de Málaga \\ dgmagna@uma.es
}

Resumen: El sistema penal español está fuertemente asentado en el principio de legalidad y viene de una tradición de codificación basada en el derecho penal clásico, que podría calificarse como derecho penal garantista. En los últimos años sin embargo hay una tendencia a llevar a cabo reformas penales a menudo y la mayoría de ellas han incrementado el rigor punitivo, ampliando los tipos delictivos, subiendo las penas y haciendo el sistema penitenciario menos flexible, especialmente para algunos delitos. Los resultados de una reciente investigación sobre cada una de las fases del sistema penal español apuntan a que el modelo político-criminal de la seguridad ciudadana estaría desplazando al modelo garantista. Sin embargo, hay ciertos ámbitos que parecen resistir esta deriva punitiva y arrojan cierto optimismo frente a la tendencia al cambio de modelo. En este trabajo se describe la realidad del sistema penal español en cada una de sus fases y se presentan algunos ejemplos de propuestas y alternativas viables frente al recurso excesivo al Derecho penal.

Palabras clave: sistema penal español, modelo penal de la seguridad ciudadana, rigorismo punitivo, uso excesivo del derecho penal, alternativas.

\begin{abstract}
The Spanish penal system is strongly established on the principle of legality and comes from a codification tradition, based on the classical liberal criminal law, which could be classified as a procedural justice system. In recent years there is a tendency to carry out penal reforms very often and most of them have increased punitiveness by widening the categories of crimes, raising the penalties, and making the penitentiary system less flexible, especially for some criminal offences. The results of a recent thorough study of each stage of the Spanish penal system show that the model of law and order is displacing the procedural justice system. However, there are certain areas that seem to resist this punitive drift and show some optimism on the tendency to change the criminal policy model. This paper describes the current situation of the Spanish penal system and presents some examples of viable alternatives to the overuse of criminal law.
\end{abstract}

Keywords: Spanish penal system, law and order model, punitiveness, abuse of criminal law, alternatives.

\footnotetext{
* El presente trabajo se ha elaborado en el contexto del proyecto de investigación DER2015-67512-P financiado por el Ministerio de Economía y Competitividad de España.
} 


\section{Polít. crim. Vol. 14, No 27 (Julio 2019), Art. 4, pp. 98-121 [http://politcrim.com/wp-content/uploads/2019/06/Vol14N27A4.pdf]}

\section{Introducción}

El sistema penal español está fuertemente asentado sobre el principio de legalidad y, en consecuencia, parte de una tradición codificadora, basada en un derecho penal clásico y liberal, que se podría caracterizar como garantista. Como principio fundamental del derecho penal occidental moderno, el principio de legalidad implica que en nuestro sistema tanto las conductas consideradas delictivas como las sanciones a imponer (con límites mínimo y máximo) se encuentran previamente recogidas de manera expresa en la ley, ${ }^{1}$ incluyendo todas las circunstancias que se deben tener en cuenta para fijar la pena: participación, grado de ejecución, concursos de delitos, atenuantes y agravantes, eximentes de la responsabilidad penal, etc. ${ }^{2}$ Asimismo, también está expresamente regulado de qué manera se ejecutan las sanciones impuestas, y en qué supuestos se puede suspender dicha ejecución, sustituir una sanción, o conceder la libertad condicional, el tercer grado de ejecución penitenciaria o los permisos de salida, entre otros. ${ }^{3}$ Los jueces españoles tienen ámbitos tasados de discrecionalidad que implican poca flexibilidad en la imposición de las sanciones, y en su posterior ejecución. ${ }^{4}$

Se observa además en las últimas décadas una tendencia a abordar reformas penales muy a menudo. El Código penal español ha sufrido ya más de 30 modificaciones en sus poco más de veinte años de vigencia, atendiendo a una media de más de una reforma penal al año. La mayoría de ellas han implicado un endurecimiento de las penas o una ampliación de los tipos, mostrando una tendencia a castigar cada vez más conductas y de manera más estricta. ${ }^{5}$ Podría decirse que en general se está incrementando la aflictividad sobre el papel, pero también se está haciendo más rígido el sistema de ejecución penitenciaria, especialmente para algunos delitos. ${ }^{6}$ Los resultados de un estudio reciente en el que se han identificado estas características en cada una de las fases del sistema penal español ${ }^{7}$ aportan numerosos ejemplos de que el modelo penal garantista está siendo desplazado por el modelo de la seguridad ciudadana o de ley y orden. Esta tendencia, que diversos autores ya

\footnotetext{
${ }^{1}$ Ley Orgánica 10/1995, de 23 de noviembre, del Código Penal español, y leyes penales especiales.

${ }^{2}$ Artículos 61 a 79 del Código penal español.

${ }^{3}$ Artículos 80 a 94 bis del Código penal; Ley Orgánica 1/1979, de 26 de septiembre, General Penitenciaria; y Real Decreto 190/1996, de 9 de febrero, por el que se aprueba el Reglamento Penitenciario.

${ }^{4}$ TAMARIT SUMALLA, Josep María, "Sistema de sanciones y política criminal. Un estudio de Derecho comparado europeo", Revista Electrónica de Ciencia Penal y Criminología, no 9 (2007), pp. 1-40, pp. 12 y ss., en http://criminet.ugr.es/recpc/09/recpc09-06.pdf [visitado el 25/7/2018] estudia diferentes indicadores de aflictividad y flexibilidad, concluyendo que España tiene un sistema rígido tanto sobre el papel como en la práctica. En el mismo sentido crítico respecto a la aplicación judicial de la ley, STANCU, Oana; VARONA GÓMEZ, Daniel, “¿Punitivismo también judicial? Un estudio a partir de las condenas penales por homicidio en España (2000-2013)", Revista Electrónica de Ciencia Penal y Criminología, artículo 19-12 (2017), pp. 131, en http://criminet.ugr.es/recpc/19/recpc19-12.pdf [visitado el 25/7/2018].

${ }^{5}$ Así lo pone de manifiesto DÍEZ RIPOLLÉS, José Luis, "Rigorismo y reforma penal. Cuatro legislaturas homogéneas (1996-2011). Parte I", Boletín Criminológico, artículo 2, no 141 (2013), pp. 1-5, en http://www.boletincriminologico.uma.es/boletines/142.pdf [Visitado el 25/7/2018]; DÍEZ RIPOLLÉS, José Luis, "Rigorismo y reforma penal. Cuatro legislaturas homogéneas (1996-2011). Parte II", Boletín Criminológico, artículo 3, no 142 (2013), pp. 6-10 http://www.boletincriminologico.uma.es/boletines/143.pdf [visitados el 25/7/2018].

${ }^{6}$ Por ejemplo, mediante las reformas operadas a través de las Leyes Orgánicas 7/2003 o 1/2015, entre otras.

${ }^{7}$ GARCÍA MAGNA, Deborah, La lógica de la seguridad en la gestión de la delincuencia, Marcial Pons, Madrid, 2018.
} 
GARCÍA MAGNA, Deborah "El recurso excesivo al Derecho Penal en España. Realidad y alternativas".

han puesto de manifiesto, ${ }^{8}$ parece ser una dinámica más o menos generalizada en los países occidentales, aunque por supuesto no se da con la misma intensidad en todos ellos ni tampoco de manera homogénea en todas las fases del sistema.

En España, concretamente, la iniciativa legislativa se ve influida por diversos factores que dan lugar a un incremento de la criminalización, a menudo más allá de la necesidad real de protección penal. Especialmente algunos ámbitos presentan una permeabilidad mayor a dinámicas populistas $\mathrm{y}$, por tanto, son más proclives a incorporar los discursos de los grupos de presión y, en concreto, de las víctimas. Por otra parte, también son dignos de mención, entre otros factores explicativos de este recurso excesivo al Derecho penal, los procesos legislativos determinados por los compromisos supranacionales que España ha asumido, pudiendo distinguir entre los que son de obligada transposición a la normativa interna (muy numerosos), y los que sirven de pretexto al legislador nacional para llevar a cabo reformas más amplias que lo exigido por la normativa internacional.

Respecto al primer aspecto, las propuestas político-criminales populistas se basan en argumentos más emocionales que racionales y en un desconocimiento o desatención de lo que los ciudadanos realmente demandan. ${ }^{9}$ Como la finalidad es obtener réditos electorales, las decisiones suelen tener corto alcance y los medios de comunicación juegan un papel fundamental. ${ }^{10}$ En definitiva, los políticos se centran en la opinión publicada como baremo para medir el nivel de atención sobre una determinada cuestión, justificando así la adopción de medidas punitivas (o la inacción en determinados ámbitos).

En los últimos años se han realizado diversas investigaciones empíricas que han estudiado de qué manera se producen los procesos de creación de la agenda y contextualización de los asuntos en el ámbito de la política criminal, pudiendo comprobar que, como ocurre en otros países, también en España se dan esas técnicas y se repiten los mismos patrones. ${ }^{11}$

\footnotetext{
${ }^{8}$ Entre otros muchos y desde variados enfoques, DÍEZ RIPOLLÉS, José Luis, "El abuso del sistema penal", Revista Electrónica de Ciencia Penal y Criminología, 19-01 (2017), pp. 1-24, en http://criminet.ugr.es/recpc/19/recpc19-01.pdf [visitado 25/7/2018]; BRANDARIZ GARCÍA, José Ángel, El gobierno de la penalidad. La complejidad de la Política criminal contemporánea, 2014; SANZ MULAS, Nieves, Política Criminal. Actualizada a las reformas de 2015, 2016; HUSAK, Douglas, Sobrecriminalización. Los limites del Derecho penal, 2013; GARLAND, David, The Culture of Control. Crime and Social Order in Contemporary Society, The University of Chicago Press, Chicago, 2001.

${ }^{9}$ Los estudios sobre actitudes frente a la delincuencia ponen de manifiesto que los españoles no son especialmente punitivos. Entre otros, VARONA GÓMEZ, Daniel, “Somos los españoles punitivos?: Actitudes punitivas y reforma penal en España, Indret: Revista para el Análisis del Derecho, $\mathrm{n}^{\circ} 1$ (2009), pp. 1-31, en http://www.indret.com/code/getPdf.php?id=1193\&pdf=599.pdf [visitado el 20/7/2018].

${ }^{10}$ Respecto a los tres vértices del triángulo de toma de decisiones: los políticos, los medios de comunicación y la opinión pública, ver, entre otros, MEDINA ARIZA, Juan José, "Discursos políticos sobre seguridad ciudadana en la historia reciente de España", 2004, pp. 1299-1320; y CRIADO OLMOS, Henar, "¿Qué temas destacan los partidos? El discurso del PP y el PSOE durante las campañas de 1996 y 2000 en España", Revista Internacional de Sociología, Vol. 63, nº 41 (2005), pp. 69-91.

${ }^{11}$ Entre otros, GARCÍA ARÁN, M.; PERES-NETO, L., "Discursos mediáticos y reformas penales de 2003", 2008; POZUELO PÉREZ, Laura, La política criminal mediática. Génesis, desarrollo y costes, 2014; VARONA GÓMEZ, Daniel, "Medios de comunicación y punitivismo", Indret, no 1 (2011), pp. 1-35, en http://www.indret.com/code/getPdf.php?id=1428\&pdf=791_1.pdf [visitado el 25/7/2018], RECHEA ALBEROLA, Cristina; FERNÁNDEZ MOLINA, Esther, Los discursos sobre seguridad ciudadana y lucha contra la delincuencia en la prensa española, 2006; y GARCÍA MAGNA, Deborah; CEREZO
} 


\section{Polít. crim. Vol. 14, No 27 (Julio 2019), Art. 4, pp. 98-121 [http://politcrim.com/wp-content/uploads/2019/06/Vol14N27A4.pdf]}

Es necesario, por tanto, aludir de manera especial a los grupos de presión que influyen en la toma de decisiones legislativas, incluyendo víctimas, ${ }^{12}$ operadores jurídicos y expertos, ${ }^{13} \mathrm{y}$ otros colectivos como las propias bases de los partidos políticos (think tank),${ }^{14}$ asociaciones e instituciones que se posicionan como estandartes de la moral pública, ${ }^{15}$ partes interesadas por encontrar un nicho de negocio, ${ }^{16} \mathrm{e}$ incluso otros Estados que imponen su criterio político-criminal a través de convenios internacionales que después tienen repercusión en las decisiones internas adoptadas por los países firmantes. ${ }^{17}$

Respecto a la obligación de legislar en base a compromisos internacionales, por imposición de jurisprudencia de órganos supranacionales o la necesidad de equiparación con otros ordenamientos jurídicos, llama la atención que de las 30 leyes que han modificado el código penal actual, 14 de ellas hacen referencia expresa a dichos compromisos y 5 mencionan el derecho y la jurisprudencia comparadas. Si se contabilizan las alusiones concretas realizadas en las exposiciones de motivos, hay 69 referencias a instrumentos internacionales o europeos, 11 a lo que otros países regulan en sus ordenamientos internos o a lo que los tribunales internos de otros países han interpretado al respecto, y 3 a la jurisprudencia del Tribunal Europeo de Derechos Humanos. ${ }^{18}$ Valorando en concreto

DOMÍNGUEZ, Ana Isabel, "El tratamiento del blanqueo de capitales por la prensa escrita: análisis descriptivo y valorativo", Revista Electrónica de Ciencia Penal y Criminología, 13-06 (2011), pp. 1-26, en http://criminet.ugr.es/recpc/13/recpc13-06.pdf [visitado el 20/72018], entre otros.

${ }^{12}$ Pone de manifiesto el diferente trato recibido y los distintos objetivos conseguidos por víctimas asociadas y por las que no lo están, CEREZO DOMÍNGUEZ, Ana Isabel, El protagonismo de las víctimas en la elaboración de las leyes penales, 2010, p. 35. En cualquier caso, hay ejemplos concretos de reformas penales que se han llevado a cabo por la insistencia de las víctimas en casos muy mediáticos, sobre todo en delitos sexuales y asesinatos cometidos contra menores de edad (como ocurrió con el caso de Mari Luz Cortés y la LO 5/2010, o el de Marta del Castillo y la LO 1/2015), delitos de terrorismo (a partir de la movilización de las asociaciones de víctimas), delincuencia juvenil violenta (por ejemplo, tras el caso Sandra Palo y las reformas de la LO 15/2003 y LO 8/2006), y violencia de género (con la presión de grupos feministas en la elaboración de diversas leyes, como la LO 5/2010). Respecto a este último proceso, aporta una visión distinta MAQUEDA ABREU, María Luisa, “¿Es la estrategia penal una solución a la violencia contra las mujeres? Algunas respuestas desde un discurso feminista crítico", en Indret 4/2007, pp. 1-43, pp. 10 y ss. (2007), en http://www.indret.com/code/getPdf.php?id=1045\&pdf=475_es.pdf [visitado el 20/7/2018].

${ }^{13}$ Grupo de Estudios de Política Criminal, la plataforma Otro Derecho Penal es Posible, Jueces para la Democracia, etc., aunque podría decirse que normalmente el legislador no suele escuchar demasiado a los expertos, como pone de manifiesto BECERRA MUÑOZ, José, "La toma de decisiones legislativas penales", Revista Española de Derecho Constitucional, $\mathrm{n}^{\mathrm{o}} 99$ (2013), pp. 125-158, p. 133, en https://dialnet.unirioja.es/descarga/articulo/4560811.pdf [visitado el 25/7/2018].

${ }^{14}$ En España, destacan los grupos de estudio del Partido Popular (Fundación para el Análisis y los Estudios Sociales, FAES) y del Partido Socialista Obrero Español (Fundación IDEAS y Alternativas para el Progreso).

${ }^{15}$ En ámbitos con un fuerte componente ético, como el aborto, la eutanasia o la manipulación genética, constituyen en España un importante grupo de presión las instituciones eclesiásticas a través de sus órganos de gobierno (la Conferencia Episcopal) y también asociaciones como el Foro de la Familia, Hazte Oír, la plataforma Derecho a Vivir, o Familia y Dignidad Humana.

${ }^{16}$ La LO 1/2015, por ejemplo, ha incorporado los programas de cumplimiento en el ámbito de las personas jurídicas, y ha dado un papel más relevante a los vigilantes de seguridad privada en los delitos contra el orden público.

${ }^{17}$ Lo que ha ocurrido, por ejemplo, con Estados Unidos en el ámbito de drogas (war on drugs) o de la propiedad intelectual, como pone de manifiesto RANDO CASERMEIRO, Pablo, "La influencia de los grupos de presión en la política criminal de la propiedad intelectual. Aspectos globales y nacionales", en RECPC, 17 (3) (2015), pp. 1-47, pp. 23 y ss., en http://criminet.ugr.es/recpc/17/recpc17-03.pdf [visitado el 20/7/2018]

${ }^{18}$ GARCÍA MAGNA, La lógica de la seguridad, cit. nota ${ }^{\circ} 7$, pp. 140 y ss. 
GARCÍA MAGNA, Deborah "El recurso excesivo al Derecho Penal en España. Realidad y alternativas".

algunas de esas reformas justificadas en dichas exigencias, se observa que algunas resultan muy punitivas, ${ }^{19}$ y que otras son utilizadas por el legislador nacional para ir más allá de lo exigido por imperativo supranacional. ${ }^{20}$

Dado que parto de un enfoque crítico con la deriva punitiva del sistema penal español, y al margen de la necesidad de sentar las bases de un nuevo modelo que sirva de alternativa al de la seguridad ciudadana, que deberá ser desarrollado en otro lugar, ahora pretendo identificar algunas propuestas y prácticas de signo opuesto a dicha tendencia. En ese sentido, en las páginas que siguen se va a describir la realidad del sistema penal español en cada una de sus fases, para posteriormente señalar algunos ejemplos de resistencia al cambio de modelo que ponen de manifiesto la viabilidad de enfoques alternativos en la gestión de la delincuencia.

Como se describirá en estas páginas, aunque no existan cifras alarmantes de delincuencia en España y los expertos consideren pertinente que se disminuya la presión penal en algunos ámbitos, podría parecer que ello solo se podría producir por razones utilitarias en un contexto de crisis económica, si se llegase a la conclusión de que un sistema con una población penitenciaria tan elevada es insostenible. En cualquier caso, aunque resulte poco probable que en el futuro inmediato se lleven a cabo políticas descriminalizadoras que suavicen el control penal formal, la tendencia general hacia un uso excesivo del Derecho penal parece encontrar atisbos de optimismo en algunos ámbitos que, bien por permanecer ajenos a la deriva punitiva, bien por resistencia al cambio, plantean alternativas viables ante el cambio de modelo.

\section{El recurso excesivo a la respuesta legislativa penal}

\subsection{Presupuesto de la intervención penal: la realidad de la delincuencia}

España no tiene tasas de delincuencia elevadas, como se puede observar en el análisis comparado entre los países de su entorno. ${ }^{21}$ De hecho, la tasa de delincuencia española se

\footnotetext{
${ }^{19}$ Por ejemplo, la Decisión marco 2004/68/JAI, que establece un concepto muy amplio de pornografía infantil (recogido en el artículo 189 del CP); la Decisión Marco 2008/919/JAI, sobre conductas preparatorias y de participación en delitos de terrorismo (artículos 572, 575, 578 y 579 CP); la Directiva 2008/99/CE sobre protección del medioambiente que puede estar vulnerando los principios de ultima ratio y de legalidad del Derecho penal (artículo 326 CP); la Decisión Marco 2008/913/JAI, sobre delitos de odio, que podría vulnerar el principio de subsidiariedad (artículo 510); la Directiva 2011/36/UE, que impone para el delito de trata una pena mínima igual que la que la que establece la Directiva 2014/62/UE para los delitos de falsificación de moneda (artículos 177 bis y $386 \mathrm{CP}$ ), vulnerando el principio de proporcionalidad.

${ }^{20}$ Por ejemplo, sucede en la regulación de los delitos de odio de manera más amplia que lo que establece la Decisión Marco 2008/913/JAI (artículo 510 CP); la regulación del decomiso en el artículo 127 bis, y del perfil genético en el artículo 129 bis, de manera más extensa que lo que dicen la Directiva 2014/42/UE y el Convenio del Consejo de Europa de Lanzarote de 2007, respectivamente; en delitos de terrorismo respecto a la Resolución 2178 del Consejo de Seguridad de la ONU de 2014 (artículo 577 CP); o la edad de consentimiento sexual que no se fija en el Convenio del Consejo de Europa para la protección de los niños contra la explotación y el abuso sexual de 2007, a pesar de lo que dice la reforma de la LO 1/2015.

${ }^{21}$ Según datos de detenciones policiales recogidos en el European Sourcebook of Crime and Criminal Justice Statistics, 5th edition, 2014, p. 32. Disponible en:
} 


\section{Polít. crim. Vol. 14, No 27 (Julio 2019), Art. 4, pp. 98-121 [http://politcrim.com/wp-content/uploads/2019/06/Vol14N27A4.pdf]}

encuentra muy por debajo de la de la mayoría de los países de la Europa de los 15. Si se analizan los datos oficiales disponibles sobre hechos conocidos, se observa que, en términos absolutos, hubo una fase ligeramente ascendente desde 2000 hasta 2008, seguida de un periodo descendente que dura hasta la actualidad. ${ }^{22}$ Cuando se analiza la evolución de la tasa de criminalidad (número de delitos en relación con la población), se confirman dichos datos, presentando tendencias menos acentuadas.

Resulta muy conveniente completar los datos policiales con la información que proporcionan otros instrumentos de medición, tales como las encuestas de victimización. ${ }^{23}$ Aunque España solo ha participado en las encuestas europeas de 1989 y $2005,{ }^{24}$ se cuenta con datos a nivel nacional algo más recientes que, por lo general, ponen de manifiesto cifras bajas y ligeramente en descenso. De hecho, concretamente para el periodo entre 2000 y 2005, a pesar de que las cifras policiales eran ascendentes, las encuestas señalaban una tendencia descendente. ${ }^{25}$

Por lo que respecta a los delitos más frecuentes, tal como se recogen agrupados en las estadísticas oficiales en relación con su clasificación en el Código penal (gráfico 1), destacan en primer lugar los delitos contra el patrimonio, constituyendo una parte importante de los mismos los delitos de robo con fuerza y los hurtos, que representan más de la mitad del total de los delitos cometidos (51,2\%). En segundo lugar, se sitúan los delitos contra las personas, entre los que se agrupan los delitos de homicidio y asesinato $(0,05 \%)$, lesiones $(4,8 \%)$, malos tratos $(4,0 \%)$ y contra la libertad $(5,7 \%)$. En tercer lugar, se encuentran los delitos contra la seguridad colectiva, que agrupan los de tráfico de drogas $(0,6 \%)$ y contra la seguridad vial $(2,2 \%)$. En cuarto y quinto lugar se sitúan los delitos contra el orden público y contra la administración de justicia, seguidos de otros delitos cuya representación es menor que la de estos grupos (las falsedades un 0,9\% del total, los delitos contra la libertad sexual un $0,5 \%$ y los delitos contra las relaciones familiares un $0,4 \%$ ). Si se desagregan los datos que de manera conjunta ofrece el Ministerio del Interior, la clasificación varía solo ligeramente.

Gráfico 1. Delitos más frecuentes por grupos $(2016)^{26}$

http://www.heuni.fi/material/attachments/heuni/reports/qrMWoCVTF/HEUNI_report 80_European_Sourceb ook.pdf [visitado el 25/7/2018].

${ }^{22}$ Según datos del Ministerio del Interior del Gobierno de España. Anuarios Estadísticos. Disponibles en: http://www.interior.gob.es/web/archivos-y-documentacion/anuario-estadistico-de-2016

${ }^{23}$ Tal como ponen de manifiesto AEBI, Marcelo; LINDE, Antonia, "El misterioso caso de la desaparición de las estadísticas policiales españolas", Revista Electrónica de Ciencia Penal y Criminología, no 12-07 (2010), pp. 1-30, en http://criminet.ugr.es/recpc/12/recpc12-07.pdf [visitado el 22/7/2018], las fuentes oficiales adolecen de defectos.

${ }^{24}$ European Sourcebook of Crime and Criminal Justice Statistics, 2014, cit. nota no21, p. 342.

${ }^{25}$ GARCÍA ESPAÑA, Elisa; DÍEZ RIPOLLÉS, José Luis; PÉREZ JIMÉNEZ, Fátima; BENÍTEZ JIMÉNEZ, María José; CEREZO DOMÍNGUEZ, Ana Isabel, "Evolución de la delincuencia en España. Análisis longitudinal con encuestas de victimización", Revista Española de Investigación Criminológica: REIC, $\mathrm{n}^{\circ} 8$ (2010), pp. 1-27, pp. 9 y ss., en https://reic.criminologia.net/index.php/journal/article/view/52/49 [visitado el 25/7/2018]

${ }^{26}$ Elaboración propia a partir de datos del Ministerio del Interior. 
GARCÍA MAGNA, Deborah “El recurso excesivo al Derecho Penal en España. Realidad y alternativas".

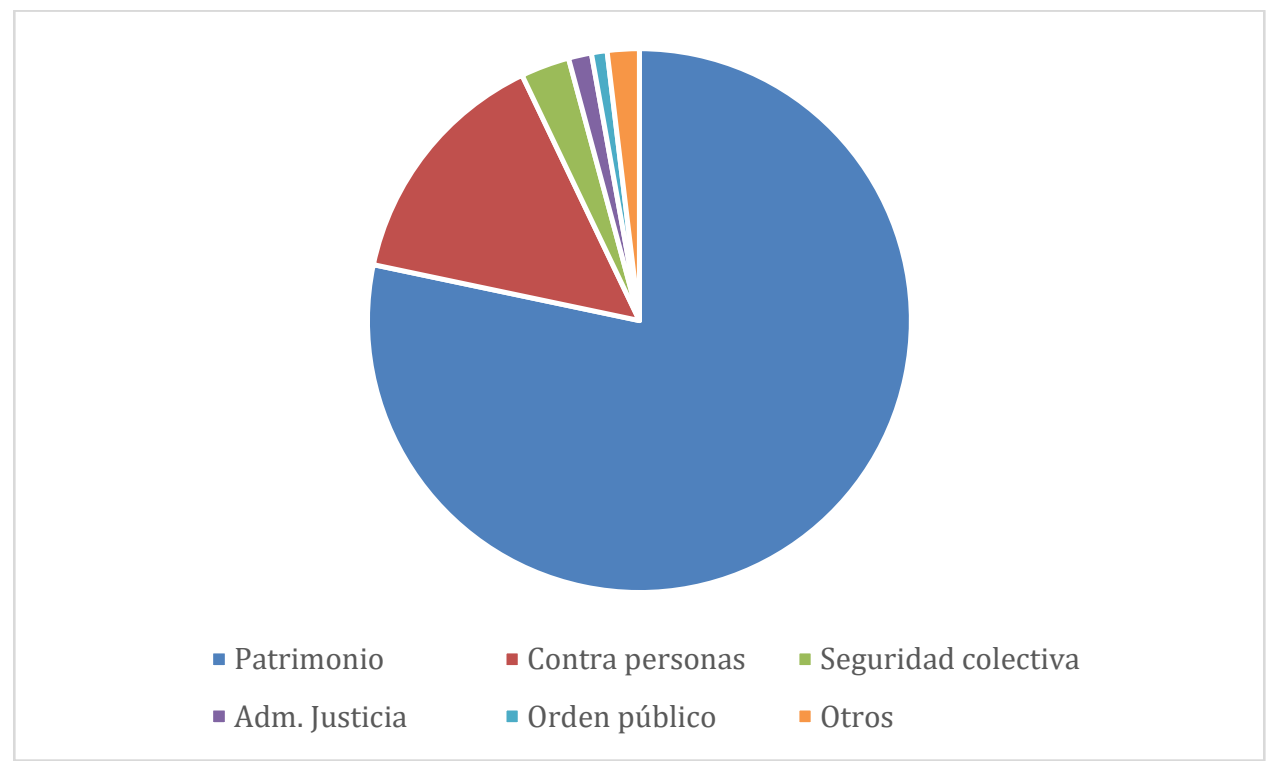

\subsection{Propuestas y alternativas viables frente a un enfoque punitivista en el ámbito legislativo}

En la fase legislativa la elevada exposición pública puede dar lugar a estrategias de bifurcación por las que, mientras se producen reformas muy mediáticas que agravan los delitos más expuestos a la opinión pública (como el terrorismo o los delitos sexuales), también se llevan a cabo otras que pasan desapercibidas y que suponen una menor intervención penal (como ha ocurrido recientemente con los delitos de tráfico de drogas). Pueden distinguirse dos posibilidades de rebaja de la presión punitiva en el ámbito legislativo: la legalización (aun controlada) y la descriminalización (pasando a una regulación en otro ámbito del derecho, por ejemplo, administrativo o civil).

Por lo que respecta a la primera de las opciones, en la doctrina es frecuente encontrar voces que consideran que en determinadas circunstancias algunas conductas deberían quedar al margen de la regulación penal. Es el caso del aborto, por ejemplo, que recientemente ha sido modificado, pasando del anterior sistema de indicaciones a un sistema mixto de indicaciones y plazos. ${ }^{27}$ Del mismo modo, se ha planteado la posibilidad de despenalizar la eutanasia bajo ciertas condiciones y garantías, realizando una interpretación del derecho a la vida en el que se integre la disponibilidad de la propia vida a fin de reconocer el derecho

\footnotetext{
${ }^{27}$ Se muestran a favor del sistema de plazos, ROPERO CARRASCO, Julia, "La insuficiencia del sistema de indicaciones en el delito de aborto", en Anuario de Derecho Penal y Ciencias Penales, Vol. LVI-2003, pp. 211-252, pp. 240 y ss., LAURENZO COPELLO, Patricia, Dogmática y Política Criminal del aborto, 2012, pp. 101 y ss., GONZÁLEZ CUSSAC, José Luis; VALLDECABRES ORTIZ, Isabel, "El Anteproyecto de Ley Orgánica de salud sexual y reproductiva y de la interrupción voluntaria del embarazo", en Revista Xurídica Galega, $\mathrm{n}^{\circ}$ 59, 2008, pp. 13-28, p.18. Por otro lado, en contra de la despenalización, incluso en algunos casos que actualmente se consideran justificados, SILVA SÁNCHEZ, Jesús María, "Los indeseados como enemigos: la exclusión de seres humanos del status personae", en Revista Electrónica de Ciencia Penal y Criminología, núm. 09-01 (2007), pp. 1-18, en http://criminet.ugr.es/recpc/09/recpc09-01.pdf [visitado el 25/7/2018]
} 


\section{Polít. crim. Vol. 14, No 27 (Julio 2019), Art. 4, pp. 98-121 [http://politcrim.com/wp-content/uploads/2019/06/Vol14N27A4.pdf]}

a morir con dignidad. ${ }^{28}$ Igualmente se ha planteado por la doctrina, y se encuentra presente en el debate público la posibilidad de despenalizar algunos delitos de tráfico de drogas, coincidiendo con un cambio de paradigma en Estados Unidos y Latinoamérica, que ahora parecen considerar el problema de las drogas como un asunto de salud pública más que de seguridad. Ello está dando paso a ciertas propuestas de reducción de riesgos a través de regulaciones del consumo controlado. ${ }^{29}$ Por otra parte, se ha apuntado la conveniencia de despenalizar algunas conductas leves contra el patrimonio o imponer medidas no privativas de libertad en los que no se haya usado violencia o intimidación. ${ }^{30}$ Asimismo, hay quien entiende que el Derecho penal juvenil debería tener su propio catálogo de delitos, menos amplio que el del Código penal de adultos, que se aplica actualmente. ${ }^{31}$

Por lo que respecta a la opción de la descriminalización, siguiendo las propuestas de algunos expertos, ${ }^{32}$ la última reforma del Código penal español (en 2015) ha eliminado las faltas, llevando algunas de ellas al ámbito del derecho administrativo. ${ }^{33}$ Sin embargo, buena parte de dichas conductas permanecen en el ámbito penal, ahora como delitos leves y en ocasiones con penas más graves que antes. En realidad, tanto si la opción es la legalización de conductas, como si es la regulación a través de otros instrumentos normativos, las cifras de delincuencia en España indican que podría rebajarse la presión punitiva. Por ejemplo, si

\footnotetext{
${ }^{28}$ Así, REY MARTÍNEZ, Fernando, Eutanasia y derechos fundamentales, 2008, Centro de Estudios Constitucionales, p. 88; DÍEZ RIPOLLÉS, José Luis, "Eutanasia y Derecho", en Anuario de Filosofía del Derecho, $n^{\circ} 12$ (1995), pp. 83-114, p. 85, en: https://dialnet.unirioja.es/descarga/articulo/142328.pdf, [visitado 25/7/2018], quien considera preeminente la voluntad del afectado; CARBONELL MATEU, Juan Carlos, "Suicidio y eutanasia en el Código penal de 1995", 1997, quien coloca el acento en la dignidad y libre voluntad de la persona; GARCÍA RIVAS, Nicolás, "Despenalización de la eutanasia en la Unión Europea: autonomía e interés del paciente", en Revista Penal, $\mathrm{n}^{\mathrm{o}} 11$ (2003), pp. 15-30, quien hace un estudio comparado; GARCÍA ARÁN, Mercedes, "Eutanasia y disponibilidad de la propia vida", en Cuadernos de Derecho Judicial (1995), p. 26, se refiere a la presunción del consentimiento cuando el sujeto no puede prestarlo por sí mismo; también el informe del GRUPO DE ESTUDIOS DE POLÍTICA CRIMINAL, Una alternativa al tratamiento jurídico de la disponibilidad sobre la propia vida, 1991.

${ }^{29}$ Así se pone de manifiesto en el Informe del Parlamento Europeo "Europa y América Latina, la lucha contra la droga y el narcotráfico", AFET-EUROLAT, 2012, pp. 12 y ss. Ver también: http://www.theguardian.com/us-news/2016/mar/29/barack-obama-drug-addiction-health-problem-not-

criminal-problem. A favor de las políticas despenalizadoras, ÁLVÁREZ GARCÍA, Francisco Javier, "La necesidad de un cambio de paradigma en el tráfico de drogas: la urgencia de su legalización", en Cuadernos de Política Criminal, 105 (2011), pp. 199-246, pp. 200 y ss.

${ }^{30}$ Así se propone, por ejemplo, en el Informe del Observatorio del Entorno Penitenciario (Red de Organizaciones Sociales del Entorno Penitenciario, ROSEP), 2016, disponible en https://plataformarosep.files. wordpress.com/2016/04/estudio-de-la-realidad-penal-y-penitenciaria-unavisic3b3n-desde-las-entidades-sociales.pdf, pp. 15 y 16. Criticando la reforma de la LO 1/2015 que, en sentido contrario al propuesto, ha incluido agravantes en el hurto y eleva la falta a delito leve, DEL CARPIO DELGADO, Juana, "Sobre la innecesaria reforma de los delitos de hurto. A propósito del Anteproyecto de 2012 de reforma del Código penal", en Foro Nueva Época, vol. 16, n 2 (2013), pp. 83-137.

${ }^{31}$ Entre otros, CRUZ MÁRQUEZ, Beatriz, "Presupuestos de la responsabilidad penal del menor: Una necesaria revisión desde la perspectiva adolescente", en Anuario de la Facultad de Derecho de la Universidad Autónoma de Madrid, "El menor ante el Derecho en el siglo XXI", 15 (2011), p. 241-269, p. 256.

${ }^{32}$ El Pleno del Consejo General del Poder Judicial de 28 de junio de 2012, emitió un informe llamado "Propuestas para la reducción de la litigiosidad", pp. 46 y ss., en el que se proponía la destipificación de algunas faltas, pasando al ámbito civil o administrativo, y que los jueces de paz pudieran juzgar las faltas penales.

${ }^{33}$ Por ejemplo, en el ámbito de la LO 4/2015, de 30 de marzo, de protección de la seguridad ciudadana.
} 
se atiende al número de delitos de tráfico de drogas (gráfico 5), se observa que es una cifra baja y que por tanto estaría justificado despenalizar ciertas conductas y regular otras para evitar daños a menores de edad y personas vulnerables, dejando al margen aquellas realizadas entre adultos con plena capacidad. En un sentido similar, se llama la atención por la doctrina sobre algunas conductas en el ámbito de la seguridad vial que ya quedan suficientemente abarcadas por el derecho administrativo. ${ }^{34}$

Por último, no puede decirse que los ámbitos en los que ha habido una relajación de la intensidad punitiva hayan dejado espacios de desprotección de la ciudadanía. En efecto, si analizamos, por ejemplo, dos de las pocas reformas que han suavizado la intervención penal, en el aborto y en el tráfico de drogas, ambas de 2010, comprobamos que no se ha elevado el número de delitos desde entonces. ${ }^{35}$ Ello indica que probablemente sería viable llevar a cabo reformas parecidas en otros ámbitos, en sentido contrario a la tendencia hacia un mayor rigor punitivo.

\section{El recurso excesivo a instrumentos punitivos en la persecución de ciertas conductas y en la imposición judicial de la ley}

\subsection{La realidad de la persecución del delito en España}

Tal como se observaba en el apartado 1.1, la tasa de delincuencia española ha permanecido en cifras bajas durante todo el período analizado, mostrando una leve tendencia al alza hasta 2008, y a la baja hasta la actualidad. Los datos sobre persecución y eficacia policial (hechos esclarecidos, detenciones y condenados) se muestran en general coincidentes con dichas tendencias, siendo preciso hacer algunas precisiones. Puede decirse que la tasa de detenciones presenta en general una tendencia al alza (gráfico 2), aunque esta comienza a ser ligeramente descendente desde 2011. Mucho más estable al alza se muestra la evolución del porcentaje de delitos esclarecidos, con ligeros descensos, aunque igualmente en los últimos años se ha producido un descenso significativo (gráfico 3). El porcentaje de condenados sobre el total de detenidos es marcadamente ascendente hasta 2008, con un periodo descendente hasta 2011, para volver a remontar significativamente desde entonces (gráfico 4).

\footnotetext{
${ }^{34}$ En ese sentido, respecto al delito de conducción sin permiso de conducir, MIRÓ LLINARES, Fernando, “El 'moderno' Derecho penal vial y la penalización de la conducción sin permiso”, en Indret, no 3 (2009), pp. $1-54$, p. 28, quien considera que dicha circunstancia como mucho debería imponerse como agravante en casos de conducción temeraria.

${ }^{35}$ Según los datos oficiales, desde 2011 ha habido un descenso en el número de abortos, tendencia que se mantiene en 2016, a pesar de que la ley actual ya no es solo de supuestos sino de plazos, no siendo preciso alegar motivo alguno cuando el aborto se realiza antes de las 14 semanas de embarazo, según establece la LO 2/2010, de 3 de marzo, de salud sexual y reproductiva y de la interrupción voluntaria del embarazo, arts. 13 y 14. Así se recoge en el trabajo de EXPÓSITO CAMACHO, Palmira, "La situación actual del aborto en España. Valoración provisional de la eficacia de la ley orgánica 2/2010 de salud sexual y reproductiva y de la interrupción voluntaria del embarazo", en Boletín Criminológico, artículo 3/2017, mayo-junio, no 170 (2017), pp. 1-17, en http://www.boletincriminologico.uma.es/boletines/170.pdf, [visitado el 22/7/2018]. Según los Balances de criminalidad del Ministerio del Interior, tampoco se han elevado los delitos de drogas, a pesar de la bajada de pena y de la atenuación incluidas en el artículo 368 del Código penal en 2010, y además la reforma legislativa ha supuesto un descenso importante de la población carcelaria, como se verá más adelante.
} 
Polít. crim. Vol. 14, No 27 (Julio 2019), Art. 4, pp. 98-121

[http://politcrim.com/wp-content/uploads/2019/06/Vol14N27A4.pdf]

Gráfico 2. Tasa de detenciones/1000 infracciones $(2000-2016)^{36}$

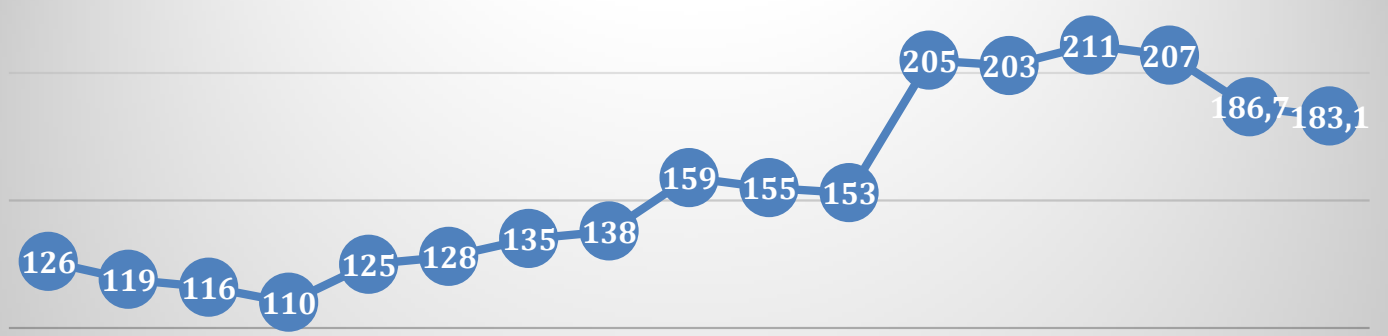

20002001200220032004200520062007200820092010201120122013201420152016

Gráfico 3. Delitos esclarecidos (\% sobre hechos conocidos) $(2000-2016)^{37}$

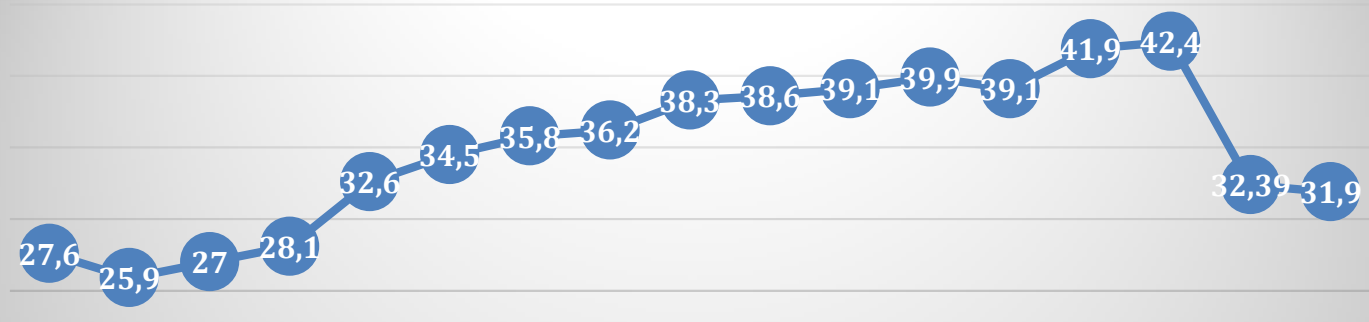

20002001200220032004200520062007200820092010201120122013201420152016

Gráfico 4. Condenados (\% sobre detenidos) $(2000-2016)^{38}$

\footnotetext{
${ }^{36}$ Elaboración propia a partir de datos del Anuario estadístico Ministerio Interior.

${ }^{37}$ Elaboración propia a partir de datos del Anuario estadístico Ministerio Interior.

${ }^{38}$ Elaboración propia a partir de datos del Anuario estadístico Ministerio Interior y del Instituto Nacional de Estadística.
} 
GARCÍA MAGNA, Deborah “El recurso excesivo al Derecho Penal en España. Realidad y alternativas".

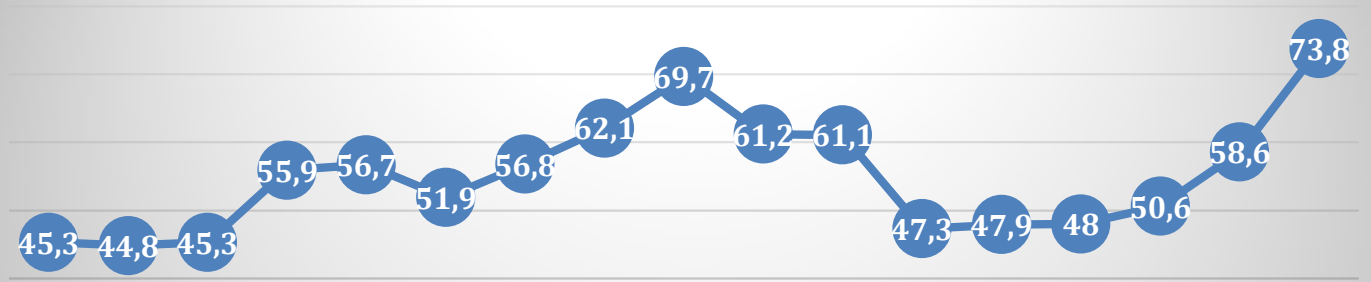

20002001200220032004200520062007200820092010201120122013201420152016

En cuanto a la distribución de condenas por clase de delito, según los datos proporcionados por el Instituto Nacional de Estadística (gráfico 5), se sitúan en primer lugar los delitos contra el patrimonio (33,6\%), seguidos de los delitos contra la seguridad vial $(23,8 \%)$ y lesiones $(15,1 \%)$. En cuarto lugar aparecen los delitos contra la libertad $(5,9 \%)$ y a continuación, los de tráfico de drogas (3,3\%), contra la libertad sexual $(0,7 \%)$ y los homicidios/asesinatos $(0,3 \%)$. Llama la atención que los delitos contra la seguridad vial, que ocupan el quinto lugar en la clasificación de hechos conocidos, sin embargo son los segundos que más condenas reciben.

Gráfico 5. Distribución de condenas por tipologías delictivas (2016) ${ }^{39}$

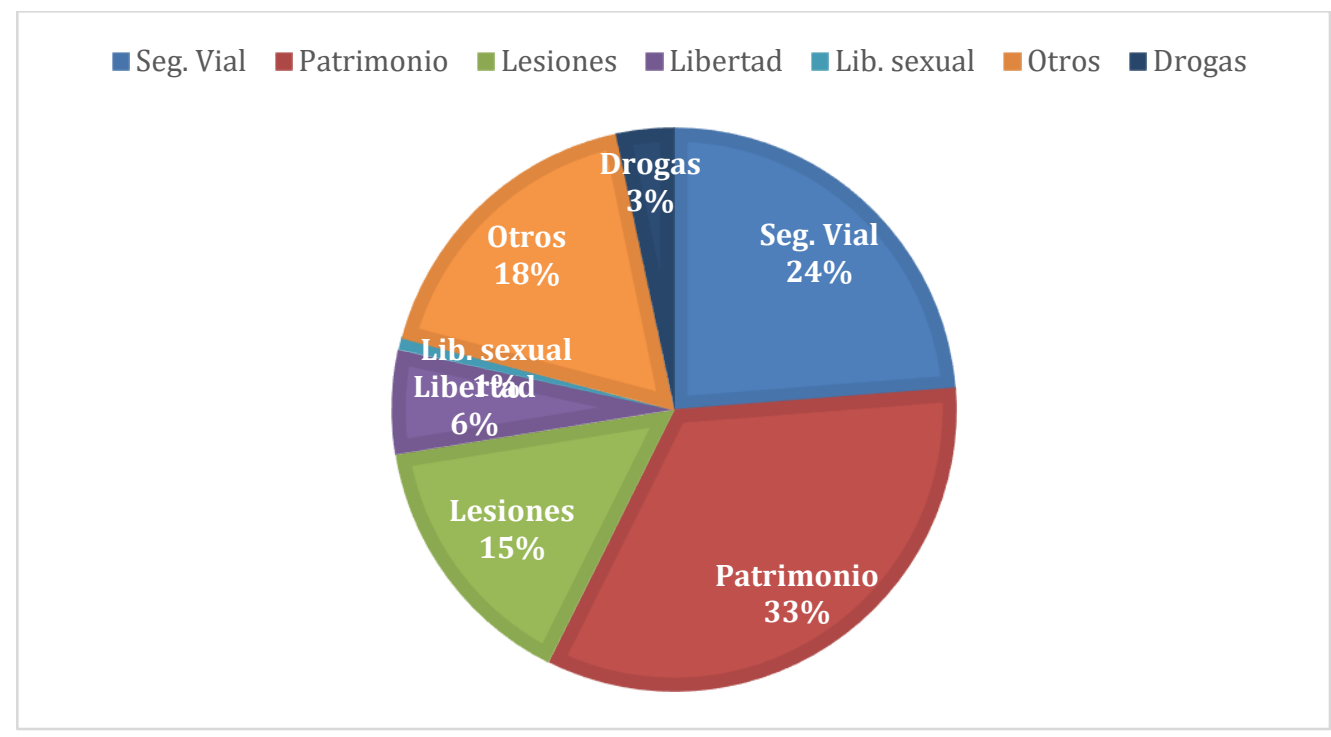

\footnotetext{
${ }^{39}$ Elaboración propia a partir de datos del Instituto Nacional de Estadística, 2014.
} 


\section{Polít. crim. Vol. 14, No 27 (Julio 2019), Art. 4, pp. 98-121 [http://politcrim.com/wp-content/uploads/2019/06/Vol14N27A4.pdf]}

\subsection{Propuestas y alternativas menos punitivas en el ámbito de la persecución penal. La mediación y otras formas de resolución de conflictos}

El Derecho penal español se basa en el principio de legalidad, fuertemente asentado, por lo que la regla general es que se persigan aquellos delitos sobre los que se tiene noticia. ${ }^{40} \mathrm{La}$ mayoría de los delitos recogidos en el Código penal español son públicos, es decir, que han de perseguirse cuando las autoridades tengan conocimiento de que se han cometido. Una pequeña parte son semipúblicos y solo se persiguen a instancia de parte (por ejemplo, algunos delitos sexuales), por lo que requieren la previa denuncia del ofendido, pero una vez interpuesta, las autoridades actúan como si fuesen delitos públicos, por lo que el denunciante no puede parar el procedimiento una vez iniciado. Por último, existen algunos delitos privados que solo se persiguen en la medida en que la víctima interponga querella y posteriormente impulse el procedimiento (por ejemplo, injurias y calumnias).

No obstante, existen algunas posibilidades de aplicación del principio de oportunidad, según el cual, aunque se tenga conocimiento de que se ha cometido una conducta tipificada como infracción penal, el órgano competente podría decidir no perseguirlo o, una vez iniciada la persecución, terminar el procedimiento con una solución no penal. Se ha situado el origen de la introducción del principio de oportunidad en el sistema penal español en la regulación de las conformidades en el procedimiento abreviado y, más tarde, en los juicios rápidos. ${ }^{41}$ Pero en realidad, esta clase de acuerdos no son formas de mediación, pues entre otras cosas, no colocan en plano de igualdad a las partes. ${ }^{42}$

La reciente Ley Orgánica 41/2015 ha incorporado a la ley procesal penal la posibilidad de que el Ministerio fiscal pueda solicitar el sobreseimiento del procedimiento y el archivo por razones de oportunidad, cuando se trate de delitos leves, ${ }^{43}$ o que la propuesta del Ministerio fiscal se convierta en sentencia firme si el encausado da su conformidad. ${ }^{44}$ En ambos casos, sin embargo, se prescinde de la víctima. En realidad, en nuestro sistema solo se prevé la desjudicialización en el ámbito de menores de edad, donde los resultados son muy alentadores $^{45}$. Las experiencias en adultos no son comparables en la medida en que son en

\footnotetext{
${ }^{40}$ Ley de Enjuiciamiento Criminal (RD de 14 de septiembre de 1882), arts. 259 y ss.

${ }^{41}$ Artículos 787 y 801 de la Ley de Enjuiciamiento Criminal. La Circular 1/1989, de 8 de marzo de la Fiscalía General del Estado, punto III.C, ya decía respecto al procedimiento abreviado que el principio de consenso implicaba una actitud socializadora "que en lo posible no debe ser perturbada ni por la continuación del proceso, ni por la sumisión a la estigmatización del juicio oral".

${ }^{42}$ La doctrina critica el número elevado de juicios que acaban con sentencias condenatorias de conformidad, sin que se desarrolle la actividad probatoria en el juicio oral y, por tanto, sin suficientes garantías. Así, SÁEZ VALCÁRCEL, Ramón, "Juicios rápidos, condenas negociadas, órdenes de alejamiento y deterioro del proceso penal", en Jueces para la Democracia, n 49 (2004), pp. 3-8. Las cifras oficiales apuntan a que en 2011 entre un $48 \%$ y un $68 \%$ de procedimientos abreviados acabaron con sentencia condenatoria de conformidad.

${ }^{43}$ Artículos $963.1 .1^{\mathrm{a}}$ y $964.2^{\mathrm{a}}$ de la Ley de Enjuiciamiento Criminal, siempre que además de la escasa gravedad del hecho, no exista un interés público relevante en la persecución del delito. Ver también la Circular 1/2015 de la Fiscalía General del Estado sobre delitos leves.

${ }^{44}$ Artículo 803 bis, llamado proceso por aceptación de decreto, o procedimiento monitorio penal.

${ }^{45}$ Recogen, entre otros, la repercusión de la mediación en menores de edad sobre los índices de reincidencia, GARCÍA, Juan, ZALDÍVAR, Flor; ORTEGA, Elena; DE LA FUENTE, Leticia; SAINZ-CANTERO, Belén, Diez años de funcionamiento de la Ley Orgánica de responsabilidad penal del menor, 2012.
} 
GARCÍA MAGNA, Deborah "El recurso excesivo al Derecho Penal en España. Realidad y alternativas".

su mayoría intrajudiciales o policiales (en conductas que ni siquiera tienen relevancia penal). ${ }^{46}$ Ante la ausencia de una normativa expresa, el Consejo General del Poder Judicial ha impulsado varias experiencias piloto. ${ }^{47}$

La suspensión, la atenuación por reparación del daño ${ }^{48}$ y la sustitución de la pena también son formas de resolver el conflicto pero no pueden compararse con la mediación, ni tampoco desjudicializan, por supuesto. El juez puede condicionar la suspensión de la ejecución de la pena al cumplimiento del acuerdo alcanzado en virtud de mediación.

La mayoría de la doctrina considera que sería posible la aplicación de la mediación a los delitos leves y menos graves (sancionados con hasta 5 años de prisión). Además, las experiencias existentes revelan que es más fácil llegar a acuerdos en los delitos de carácter patrimonial que en los violentos. Se suele discutir si sería posible en los delitos de peligro abstracto, los delitos sin víctima personalizada y los delitos graves, incluido los del terrorismo. ${ }^{49}$ Otro ámbito en el que la mediación podría tener cabida es el de la ejecución de sentencias, incluyendo cualquier clase de delitos. ${ }^{50}$ En general, se critica que los delitos que llegan a mediación suelen ser siempre los mismos: conflictos familiares o vecinales de poca importancia. $^{51}$ Lo cierto es que el proyecto de reforma de la ley de enjuiciamiento criminal no establecía límites por clase de delito, sino que ponía en manos del Ministerio Fiscal decidir si era o no adecuado en función de la naturaleza del hecho. ${ }^{52}$

El Grupo de Estudios de Política Criminal también ha elaborado un informe ${ }^{53}$ en el que proponen que las conformidades se regulen de manera única para delitos con penas privativas de libertad o de derechos de hasta 5 años. Además, se propone que se haga

${ }^{46}$ DEL MORAL GARCÍA, Antonio, La mediación en el proceso penal. Fundamentos, problemas, experiencias, 2010, pp. 49-69, habla de reconocimiento legal respecto a los menores y anomia en el proceso penal de adultos.

${ }^{47}$ Realiza un repaso de muchas de ellas, CRUZ PARRA, Juan Antonio, La mediación penal. Problemática y soluciones, 2014.

${ }^{48}$ La mayoría de las veces la reparación actúa como atenuante de la responsabilidad, pero en algunos delitos tiene efectos exculpatorios (delitos contra la Hacienda pública y la Seguridad social, 305 y ss.).

${ }^{49}$ ECHANO BASALDUA, Juan Ignacio, "Mediación penal entre adultos: ámbito de aplicación en atención a la clase de infracción”, en Cuadernos penales José María Lidón, núm. 9 (2013), pp. 157-204. MARTíN DIZ, Fernando, La mediación en materia de familia y derecho penal, 2012, pp. 20 y 21, considera que, además de la prohibición legal de incluir los delitos de violencia de género, también deberían excluirse de la mediación aquellos delitos que lleven aparejada pena de prisión, y los que se cometan con violencia contra la libertad sexual.

${ }^{50}$ RUIZ SIERRA, Joana, "Víctima y mediación penal", en Noticias Jurídicas 29 de octubre (2015), en http://noticias.juridicas.com/conocimiento/articulos-doctrinales/10614-victima-y-mediacion-penal// [visitado el 25/7/2018]

${ }^{51}$ CERVELLÓ DONDERIS, Vicenta, "La mediación penal. Un instrumento para la humanización del Derecho penal", en ORTEGA JIMÉNEZ, Alfonso; COBAS COBIELLA, María Elena; BARONA VILAR, Silvia (coord.) Mediación en el ámbito civil, familiar, penal e hipotecario. Cuestiones de actualidad, 2013, Ed.: Difusión jurídica y temas de actualidad, pp. 283-302.

${ }^{52}$ Propuesta de texto articulado de Ley de Enjuiciamiento Criminal, elaborada por la Comisión Institucional creada por Acuerdo de Consejo de Ministros de 2 de marzo de 2012: Libro II, Título VI, arts. 143 a 146.

${ }^{53}$ GRUPO DE ESTUDIOS DE POLÍTICA CRIMINAL, Una alternativa a algunas previsiones penales utilitarias. Indulto, prescripción, dilaciones indebidas y conformidad procesal, 2014, Editorial Tirant lo Blanch y Grupo de Estudios de Política Criminal, pp. 46 y ss. 
participar al encausado, y que el acuerdo no implique necesariamente que el juez imponga la pena sino que pueda reducirla o incluso absolver, impidiendo graves desproporciones entre la pena propuesta y rechazada y la que finalmente se solicite por el Ministerio Fiscal.

Por último, en nuestro ordenamiento no están establecidos expresamente los casos en que, en atención al principio de oportunidad, puede haber cierta permisividad en la persecución de delitos. Algunos estudios sobre las diferencias en los delitos perseguidos por la policía, o las sentencias condenatorias impuestas por los jueces, ${ }^{54}$ sí revelan sin embargo que en algunos ámbitos parece existir una tendencia a ser menos punitivo o riguroso, a partir de ciertas interpretaciones jurisprudenciales por ejemplo en el tráfico de drogas o en los delitos urbanísticos. $^{55}$

\section{El uso excesivo de la pena de prisión}

\subsection{Realidad penitenciaria}

A pesar de no contar con una criminalidad elevada, España tiene tasas de población penitenciaria muy altas, como se observa en la comparativa europea, situándose en 2015 solo por debajo de Reino Unido y Portugal. ${ }^{56}$ En efecto, hay una falta de correspondencia entre la tendencia estable en cifras bajas de la delincuencia española y su tasa de población penitenciaria. Al comprobar que no hay un índice elevado de entradas en prisión ${ }^{57}$, y aunque el porcentaje de penas de cárcel impuestas sobre el total de condenas tiene altibajos (gráfico 6), se apunta a que el abuso de la pena de prisión en el Código penal, con penas muy largas para los delitos contra el patrimonio y relacionados con drogas, que son los más representados en la cárcel ${ }^{58}$ junto con las bajas cifras de concesión de libertad condicional $^{59}$ y un descenso en el número de medidas alternativas acordadas, ${ }^{60}$ hacen que el tiempo medio de estancia en prisión sea de los mayores de Europa (gráfico 7).

\footnotetext{
${ }^{54}$ GARCÍA MAGNA, La lógica de la seguridad, cit. nota $\mathrm{n}^{\text {o }}$ 7, pp. 223 y ss., pone de manifiesto cómo se persiguen menos y se les impone menos pena a los delitos de blanqueo de capitales, contra la hacienda pública o la ordenación del territorio, que a los de tráfico de drogas o contra el patrimonio.

${ }^{55}$ Ocurre con las bajas penas impuestas en los delitos urbanísticos, como señala GARCÉS PEREGRINA, José Manuel, "La evolución jurisprudencial de los delitos urbanísticos en la provincia de Málaga, en Jueces para la Democracia, $\mathrm{n}^{\circ} 81$, noviembre (2014), pp. 126-152; la no persecución del tráfico de drogas cuando se trata de cantidades insignificantes, como establece la Sentencia del Tribunal Supremo 920/2013, de 11 de diciembre (ROJ STS 5868/2013), entre otras muchas; o con la reticencia de los tribunales a aplicar tipos de maltrato habitual graves, dado que los leves ya tienen penas elevadas, según apuntan LAURENZO COPELLO, Patricia, "Violencia de género y derecho penal de excepción: entre el discurso de la resistencia y el victimismo punitivo", en Cuadernos de derecho judicial, no 9 (2007), pp. 31-74; y LARRAURI PIJOAN, Elena, Criminología crítica y violencia de género, 2007, Trotta, Madrid., pp. 70 y ss.

${ }^{56}$ World Prison Population List, 11th edition, 2015.

${ }^{57}$ Según datos del Informe de Estadística Penal Anual del Consejo de Europa, SPACE I 2013, España se situaba en 2012 en los últimos puestos, solo por encima de Finlandia, Italia, Bulgaria y Portugal.

${ }^{58}$ Informes generales de la Secretaría General de Instituciones Penitenciarias del Ministerio del Interior. Gobierno de España. Disponibles http://www.institucionpenitenciaria.es/web/portal/documentos/publicaciones.html

${ }^{59}$ Según datos del Informe de Estadística Penal Anual del Consejo de Europa, SPACE I 2013.

${ }^{60}$ Informe del Observatorio del Entorno Penitenciario (Red de Organizaciones Sociales del Entorno Penitenciario, ROSEP), cit. nota n 28 , p. 60.
} 
GARCÍA MAGNA, Deborah "El recurso excesivo al Derecho Penal en España. Realidad y alternativas".

Gráfico 6. Condenas prisión (\% sobre total condenas) (2000-2016) ${ }^{61}$

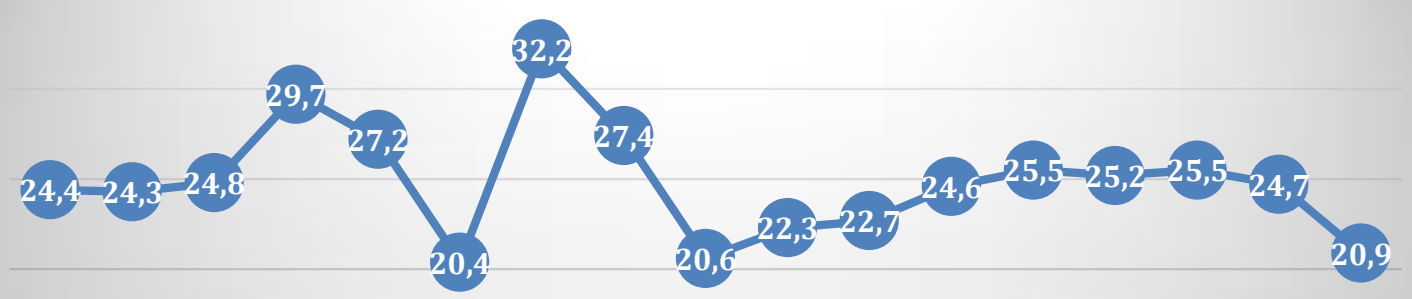

Gráfico 7. Media de estancia en prisión (meses), $2012^{62}$

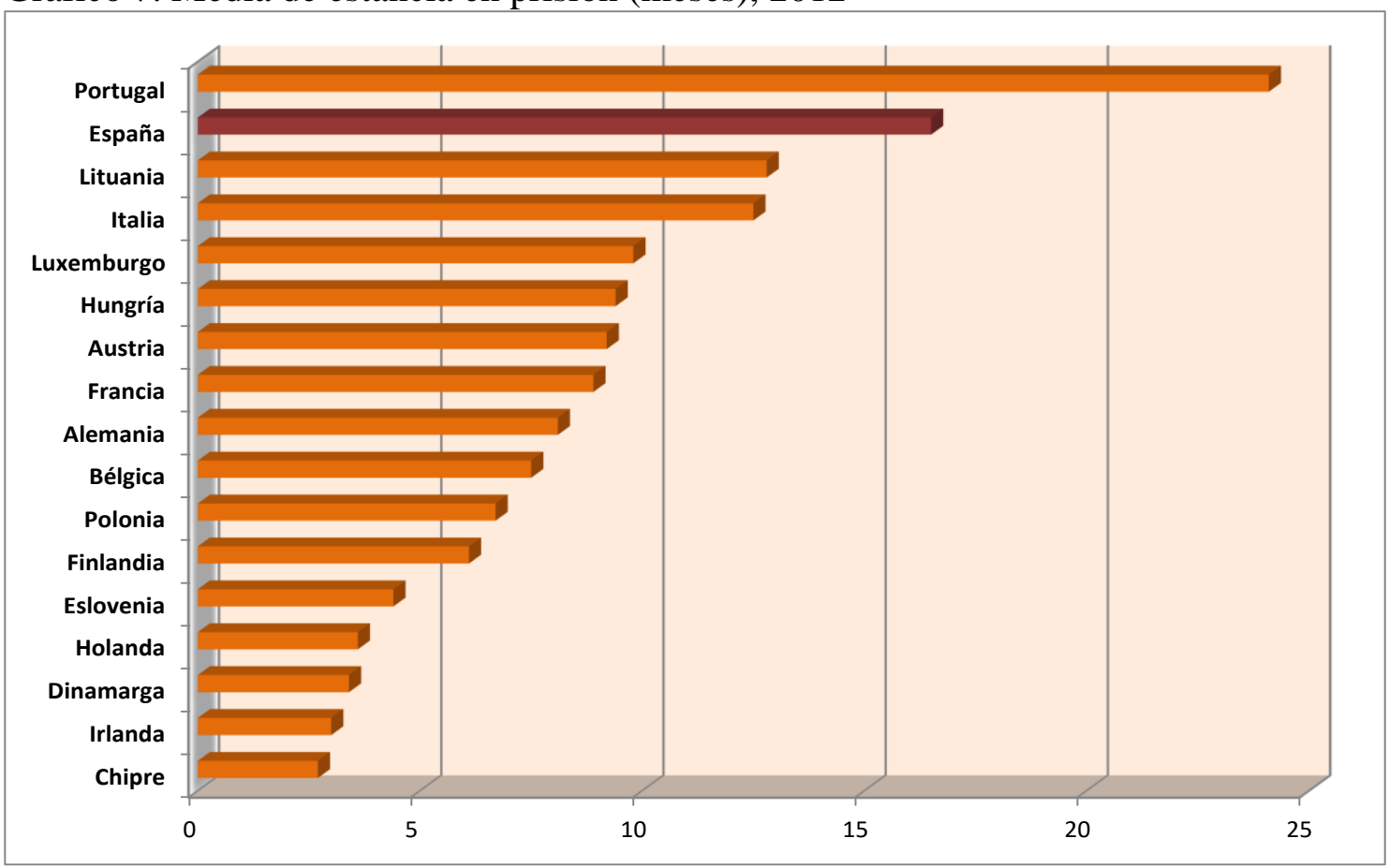

\subsection{Alternativas a la imposición de penas de prisión.}

${ }^{61}$ Elaboración propia a partir de datos del Instituto Nacional de Estadística.

62 Informe de Estadística Penal Anual del Consejo de Europa, SPACE I 2013. 


\section{Polít. crim. Vol. 14, No 27 (Julio 2019), Art. 4, pp. 98-121 [http://politcrim.com/wp-content/uploads/2019/06/Vol14N27A4.pdf]}

España tiene un Código penal que establece una o varias penas y un marco penal para cada delito, por lo que los jueces se encuentran limitados y tienen solo cierta discrecionalidad para elegir entre unas penas y otras cuando estas son alternativas, y para decidir su duración una vez aplicadas las normas de determinación de carácter obligatorio, en función de si concurren circunstancias agravantes o atenuantes, concursos de delitos, etc. Los jueces también tienen potestad para decidir sobre la sustitución y la suspensión de la ejecución de la pena, aunque con las reformas llevadas a cabo en 2003 y la última de 2015, se han incorporado requisitos muy estrictos que han disminuido dichas posibilidades ${ }^{63}$ Además, teniendo en cuenta las cifras bajas en concesión de libertad condicional y en aplicación de medidas alternativas a la prisión, no parece que nuestros operadores jurídicos estén optando por aplicar otro tipo de respuestas diferentes de la prisión.

Como se ha apuntado, nuestro sistema penal prevé penas muy elevadas sobre el papel y se caracteriza por la rigidez en la determinación y ejecución de las penas, lo que explica la larga duración media de la estancia en prisión y las altas tasas de población carcelaria. Dado que la criminalidad no es elevada, en general se podrían atenuar las sanciones, en especial en los delitos más representados en la cárcel. Así, se podrían bajar las penas y aplicar más sanciones alternativas en delitos como la seguridad vial, o en los patrimoniales sin uso de violencia. En cualquier caso, no es suficiente con prever dichos cambios en la ley, sino que es necesario que los jueces también los tengan en cuenta. ${ }^{64}$

El ejemplo de la reducción de las penas de prisión impuestas en los delitos relacionados con drogas duras y el descenso en la tasa de criminalidad en los últimos años en esta clase de delitos pone de manifiesto que este tipo de políticas no dan lugar a una menor protección de los ciudadanos, sino que probablemente se estaba haciendo un uso excesivo del Derecho penal. En el ámbito del aborto también se está produciendo un descenso en el número de los practicados en los últimos años, coincidiendo con la reforma del sistema, que ha restringido los supuestos de intervención punitiva.

\footnotetext{
${ }^{63}$ La determinación de la pena se regula en los artículos 61 y ss. del Código penal, y la sustitución y la suspensión de la ejecución en los artículos 80 y ss. Las leyes LO 15/2003 y LO 1/2015 han llevado a cabo modificaciones importantes que limitan la discrecionalidad de los jueces, llegando a hacer desaparecer prácticamente la sustitución, y convirtiendo la libertad condicional en una forma de suspensión en lugar de una fase de cumplimiento de la pena. Así, cuando el sujeto incumple las condiciones impuestas regresa a prisión a cumplir todo lo que le quedaba antes de salir, sin descontar el tiempo transcurrido fuera.

${ }^{64} \mathrm{El}$ legislador español no parece querer introducir sanciones alternativas en los delitos patrimoniales, lo que puede atender a la realidad criminológica de dichos delitos, como apunta TAMARIT SUMALLA, "Sistema de sanciones", 2007, cit. nota $\mathrm{n}^{\circ}$ 4, p. 11. Por otra parte, AEBI, Marcelo; DELGRANDE, Natalia; MARGUET, Yann, "Have community sanctions and measures widened the net of the European criminal justice systems?", en Punishment \& Society, Vol. 17(5) (2015), pp. 575-597, pp. 588 y ss., en http://journals.sagepub.com.uma.debiblio.com/doi/pdf/10.1177/1462474515615694 [visitado el 22/7/2018], apuntan que la previsión en la ley de las penas alternativas a la prisión no está generando una reducción en las tasas de población penitenciaria, sino que en realidad está expandiendo el sistema penal a conductas que antes quedaban al margen del Derecho penal, al abarcar otras conductas en lugar de aplicarse sobre las que ya incluían penas de prisión.
} 
GARCÍA MAGNA, Deborah "El recurso excesivo al Derecho Penal en España. Realidad y alternativas".

Como apuntan recientes informes, si la población penitenciaria se correspondiese con la tasa de criminalidad existente, teniendo en cuenta los datos europeos, la tasa de población carcelaria se vería reducida a la mitad. ${ }^{65}$

\section{Recapitulación, conclusiones y propuestas}

Como se ha puesto de manifiesto, España tiene una tasa de delincuencia estable y relativamente baja en comparación con los países de su entorno. Los delitos más representados en el sistema penal, tanto por número de detenciones como por sentencias condenatorias y cumplimiento en prisión, son los delitos contra el patrimonio, en especial los delitos de hurto y robo con fuerza en las cosas. Sin embargo, otros delitos, como el tráfico de drogas, no están entre los más cometidos, pero sí entre los más representados en prisión. La tasa de población penitenciaria española es una de las más altas de la Unión Europea, y con mayor tiempo medio de estancia en la cárcel, debido fundamentalmente a que la pena de prisión se prevé para la mayor parte de los delitos y, especialmente, para aquellos que están más representados en las cárceles españolas. Además, las penas previstas en el código penal son en general altas y aunque suelen imponerse en su límite mínimo por los tribunales, lo cierto es que la escasa flexibilidad del sistema español dificulta que se puedan aplicar medidas alternativas (sustitución y suspensión). Todo ello unido a que se conceden pocas libertades condicionales, terceros grados y permisos de salida, y que, con la última reforma, la libertad condicional ya no se considera una fase de ejecución de la pena sino una forma de suspensión de la misma, hace que los reclusos permanezcan en el establecimiento penitenciario mucho tiempo y, a menudo, hasta que cumplen íntegramente la cuantía de sus penas.

En definitiva, podría decirse que los procesos, dinámicas y prácticas que se dan en el sistema penal español indican que se ha producido en las últimas décadas una tendencia hacia un cambio de modelo. Así, puede afirmarse que el modelo penal de la seguridad ciudadana está desplazando al modelo garantista, aunque todavía no lo haya hecho de manera plena ni con la misma intensidad en todas sus fases. En concreto, dadas las diferentes presiones que recibe el legislador español (sociales, legales, supranacionales, etc.), este se muestra muy permeable a la influencia del modelo de ley y orden debido al grado de atención mediática al que se ve expuesto, que abona el terreno para dinámicas populistas y da lugar a normas penales crecientemente severas, en especial en algunos ámbitos. En cambio, en las últimas fases del sistema, en especial la de ejecución penitenciaria, no se evidencian cambios más allá de un leve desencanto sobre la rehabilitación. Concretamente, parece que en los operadores del sistema penitenciario se dan ciertas dinámicas de resistencia al cambio de modelo que, unidas a la lejanía del ojo público, contribuyen a que se sigan aplicando criterios y estrategias del modelo garantista y rehabilitador.

Como ya se ha expresado, no parece que la realidad de la delincuencia española haga necesarias la mayoría de las reformas que intensifican la respuesta penal (subir penas,

\footnotetext{
${ }^{65}$ Informe del Observatorio del Entorno Penitenciario (Red de Organizaciones Sociales del Entorno Penitenciario, ROSEP), cit. nota $\mathrm{n}^{\circ} 29$, pp. 71 y ss.
} 
ampliar tipos y prever privación de libertad en detrimento de otras penas alternativas). Las pocas modificaciones que han supuesto un menor rigor punitivo (por ejemplo, bajar la pena en algunos delitos contra la salud pública, lo que ha supuesto que descienda la población penitenciaria, o incorporar un sistema de plazos junto al de indicaciones en el aborto) no han llevado a un incremento de la delincuencia, por lo que parece que se podría aplicar esta misma estrategia a otros delitos. También es positivo, en cierto sentido, que existan límites a la discrecionalidad judicial, pues ello permite que no haya excesos en la fase de imposición, aunque partiendo, como se ha indicado, de límites legales que ya de por sí son elevados. En el ámbito penitenciario, a pesar de las altas tasas de población, hay algunas experiencias positivas que podrían trasladarse a otros sistemas. En concreto, destaca la construcción de numerosos centros de inserción social, la creación de módulos de respeto en las prisiones ordinarias, el alto porcentaje de jóvenes en programas de intervención, y la baja proporción de presos preventivos en relación a otros países.

Por otro lado, también es cierto que hay una escasa previsión de penas alternativas sobre el papel, pero tampoco hay recursos suficientes, ni se previeron en un principio, para aplicar dichas medidas. Por ejemplo, en el ámbito de la seguridad vial se incluyeron en 2007 más posibilidades de imponer los trabajos en beneficio de la comunidad, pero no se previeron los medios materiales para ejecutar dichas penas alternativas a la prisión, lo que dio lugar a que el número de trabajos en beneficio de la comunidad que se quedaron sin ejecutar por transcurso de la prescripción fuera enorme, debido a la falta de recursos. En 2010 se volvió a cambiar la ley para añadir la pena de multa como alternativa a la prisión o a los trabajos comunitarios, con lo que actualmente la multa es la pena más impuesta en estos delitos. ${ }^{66}$ Esto pone de manifiesto que la opción por las medidas alternativas a la prisión no siempre supone una menor presión penal sino una extensión.

En cualquier caso, las altas tasas de población penitenciaria que sigue teniendo España ponen de manifiesto que la pena privativa de libertad ocupa un lugar central. Cabe preguntarse si con la reciente reforma que ha introducido la cadena perpetua en nuestro sistema se puede entender culminada la escalada de agravación que de manera constante ha afectado al Código penal, ${ }^{67}$ o si, por el contrario, el futuro nos depara nuevas e insospechadas normas y prácticas que impliquen todavía más dureza con determinadas formas de delincuencia. La tendencia hacia penas más severas se muestra ya insostenible a nivel humanitario, pero también lo es desde el punto de vista económico, como señalan varios informes comparados. ${ }^{68}$ De hecho, en los últimos años se observa cómo la sobrepoblación carcelaria parece estar pasando factura, de manera que se han producido algunos cambios en ciertos ámbitos que han llevado a una ligera descongestión de las prisiones. ${ }^{69}$ Existen además ejemplos de alternativas al enfoque punitivo que parecen ser

${ }^{66}$ GARCÍA MAGNA, La lógica de la seguridad, 2018, cit. nota $\mathrm{n}^{\mathrm{o}} 7$.

${ }^{67}$ DÍEZ RIPOLLÉS, "Rigorismo", cit. nota no 6.

${ }^{68}$ SAMUELS, Julie; La VIGNE, Nancy; TAXY, Samuel, "Stemming the tide: Strategies to reduce the growth and cut the cost of the federal prison system", Urban Institute, 2013, en https://www.urban.org/sites/default/files/publication/24086/412932-Stemming-the-Tide-Strategies-to-

Reduce-the-Growth-and-Cut-the-Cost-of-the-Federal-Prison-System.PDF [visitado el 25/7/2018]; AEBI, Marcelo, "El coste del encarcelamiento en España y Europa”, Universidad de Málaga, 2013.

${ }^{69}$ Ha ocurrido en España, con la reforma realizada a través de la LO 5/2010, en el ámbito de los delitos contra la salud pública, que ha supuesto un descenso notable de la población penitenciaria en los últimos años. 
GARCÍA MAGNA, Deborah "El recurso excesivo al Derecho Penal en España. Realidad y alternativas".

viables sin que ello se traduzca en una menor protección de la ciudadanía frente a la delincuencia, por lo que es posible que la tendencia hacia el modelo político-criminal de la seguridad ciudadana aún pueda frenarse y dirigirse hacia un modelo distinto, cuyas bases todavía deben ser concretadas.

Algunos expertos opinan que dicha reforma atiende básicamente a una pretensión de mejorar la imagen del sistema penal ante Europa, en un momento en que las tasas de población penitenciaria habían alcanzado cifras espectaculares. 


\section{Bibliografía}

AEBI, Marcelo; LINDE, Antonia, "El misterioso caso de la desaparición de las estadísticas policiales españolas", en Revista Electrónica de Ciencia Penal y Criminología, $\mathrm{n}^{\circ}$ 12-07 (2010), pp. 1-30, en http://criminet.ugr.es/recpc/12/recpc12-07.pdf [visitado el 22/7/2018].

AEBI, Marcelo, "El coste del encarcelamiento en España y Europa", conferencia pronunciada el 18 nov. 2013, Universidad de Málaga.

AEBI, Marcelo; DELGRANDE, Natalia; MARGUET, Yann, "Have community sanctions and measures widened the net of the European criminal justice systems?", Punishment \& Society, Vol. 17 (5) (2015), pp. 575-597, en http://journals.sagepub.com.uma.debiblio.com/doi/pdf/10.1177/1462474515615694 [visitado el 22/7/2018].

ÁLVAREZ GARCÍA, Francisco Javier, "La necesidad de un cambio de paradigma en el tráfico de drogas: la urgencia de su legalización" en Cuadernos de Política Criminal, $\mathrm{n}^{\mathrm{o}}$ 105, (2011), pp.199-246.

BECERRA MUÑOZ, José, "La toma de decisiones legislativas penales", en Revista Española de Derecho Constitucional, $\mathrm{n}^{\mathrm{o}} 99$ (2013), pp. 125-158, en https://dialnet.unirioja.es/descarga/articulo/4560811.pdf [visitado el 25/7/2018].

BRANDARIZ GARCÍA, José Ángel, El gobierno de la penalidad. La complejidad de la Política criminal contemporánea, Dykinson, Madrid, 2014.

CARBONELL MATEU, Juan Carlos, "Suicidio y eutanasia en el Código penal de 1995", en GÓMEZ COLOMER, Juan Luis; GONZÁLEZ CUSSAC, José Luis (coords.), "La reforma de la justicia penal (estudios en homenaje al Prof. Klaus Tiedemann)", Universidad Jaume I, Castellón, 1997, pp. 183-202.

CEREZO DOMÍNGUEZ, A.I., El protagonismo de las víctimas en la elaboración de las leyes penales, Tirant lo Blanch, Madrid, 2010.

CERVELLÓ DONDERIS, Vicenta, "La mediación penal. Un instrumento para la humanización del Derecho penal", en ORTEGA JIMÉNEZ, Alfonso; COBAS COBIELLA, María Elena; BARONA VILAR, Silvia (coord.) Mediación en el ámbito civil, familiar, penal e hipotecario. Cuestiones de actualidad, 2013, Ed.: Difusión jurídica y temas de actualidad, Madrid, pp. 283-302.

CONSEJO GENERAL DEL PODER JUDICIAL, en sesión plenaria de 28 de junio de 2012, "Propuestas para la reducción de la litigiosidad", en http://www.poderjudicial.es/portal/site/cgpj/ [visitado 25/7/2018].

CRIADO OLMOS, Henar, "¿Qué temas destacan los partidos? El discurso del PP y el PSOE durante las campañas de 1996 y 2000 en España", en Revista Internacional de Sociología, Vol. 63, no 41 (2005), p. 69-91.

CRUZ MÁRQUEZ, Beatriz, "Presupuestos de la responsabilidad penal del menor: Una necesaria revisión desde la perspectiva adolescente", en Anuario de la Facultad de Derecho de la Universidad Autónoma de Madrid, "El menor ante el Derecho en el siglo XXI”, no 15 (2011), pp. 241-269.

CRUZ PARRA, Juan Antonio, La mediación penal. Problemática y soluciones, Autopublicacionlibros.com, 2015. 
GARCÍA MAGNA, Deborah "El recurso excesivo al Derecho Penal en España. Realidad y alternativas".

DAUNIS RODRÍGUEZ, Alberto, “Ocupación carcelaria: Hipótesis acerca del descenso de la población penitenciaria en España”, en Estudios Penales y Criminológicos, $\mathrm{n}^{\mathbf{0}} 36$ (2016), pp. 447-483.

DEL CARPIO DELGADO, Juana, "Sobre la innecesaria reforma de los delitos de hurto. A propósito del Anteproyecto de 2012 de reforma del Código penal", en Foro Nueva Época, vol. 16, nº 2 (2013), pp. 83-137.

DEL MORAL GARCÍA, Antonio, La mediación en el proceso penal. Fundamentos, problemas, experiencias, en RODRÍGUEZ-ARANA MUNOOZ, Xaime; DE PRADA RODRÍGUEZ, Mercedes; CARABANTE MUNTADA, José María (coords.) La mediación: presente, pasado y futuro de una institución jurídica, Netbiblo, España, pp. 49-69, 2010.

DÍEZ RIPOLLÉS, José Luis, “Eutanasia y Derecho”, en Anuario de Filosofía del Derecho, $\mathrm{n}^{\circ} \quad 12 \quad$ (1995), pp. 83-114, en: https://dialnet.unirioja.es/descarga/articulo/142328.pdf, [visitado 25/7/2018].

DÍEZ RIPOLLÉS, José Luis, "Rigorismo y reforma penal. Cuatro legislaturas homogéneas (1996-2011). Parte I”, Boletín Criminológico, artículo 2, no 141 (2013), pp. 1-5, en http://www.boletincriminologico.uma.es/boletines/142.pdf [Visitado el 25/7/2018].

DÍEZ RIPOLLÉS, José Luis, "Rigorismo y reforma penal. Cuatro legislaturas homogéneas (1996-2011). Parte II”, Boletín Criminológico, artículo 3, no 142 (2013), pp. 6-10, en http://www.boletincriminologico.uma.es/boletines/143.pdf [visitados el 25/7/2018].

DÍEZ RIPOLLÉS, José Luis, "La realidad del control penal en España. Política legislativa, criminalidad, reacción punitiva, percepciones sociales", conferencia, 2013.

DÍEZ RIPOLLÉS, José Luis, "El abuso del sistema penal", en Revista Electrónica de Ciencia Penal y Criminología, $\mathrm{n}^{\mathrm{o}}$ 19-01 (2017), pp. 1-24, en http://criminet.ugr.es/recpc/19/recpc19-01.pdf [visitado 25/7/2018]

ECHANO BASALDUA, Juan Ignacio, "Mediación penal entre adultos: ámbito de aplicación en atención a la clase de infracción", en Cuadernos penales José María Lidón, no 9 (2013), pp. 157-204.

EXPÓSITO CAMACHO, Palmira, "La situación actual del aborto en España. Valoración provisional de la eficacia de la ley orgánica 2/2010 de salud sexual y reproductiva y de la interrupción voluntaria del embarazo", en Boletín Criminológico, artículo 3/2017, mayo-junio (n⿳170) (2017), pp. 1-17, en http://www.boletincriminologico.uma.es/boletines/170.pdf, [visitado el 22/7/2018].

GARCÉS PEREGRINA, José Manuel, "La evolución jurisprudencial de los delitos urbanísticos en la provincia de Málaga", en Jueces para la Democracia, $\mathrm{n}^{\circ} 81$ (2014), pp. 126-152.

GARCÍA ARÁN, Mercedes, "Eutanasia y disponibilidad de la propia vida", en Cuadernos de Derecho Judicial, (1995), pp. 9-40.

GARCÍA ARÁN, Mercedes; PERES-NETO, Luis, "Discursos mediáticos y reformas penales de 2003", en GARCÍA ARÁN, M.; BOTELLA CORRAL, J., (dirs.), Malas noticias. Medios de comunicación, política criminal y garantías penales en España, Tirant lo Blanch, Madrid, 2008.

GARCÍA ESPAÑA, Elisa, "La expulsión como sustitutivo de la pena de prisión en el Código Penal de 2015. ¿De la discriminación a la reinserción?”, en Revista 
Electrónica de Ciencia Penal y Criminología, $\mathrm{n}^{\mathrm{o}}$ 18-07, (2016), pp. 1-31, en http://criminet.ugr.es/recpc/18/recpc18-07.pdf [visitado el 22/7/2018].

GARCÍA ESPAÑA, Elisa, "Extranjeros sospechosos, condenados y excondenados: Un mosaico de exclusión", en Revista Electrónica de Ciencia Penal y Criminología, $\mathrm{n}^{\mathbf{o}}$ 19-15 (2017), pp. 1-28, en http://criminet.ugr.es/recpc/19/recpc19-15.pdf [visitado el 22/7/2018].

GARCÍA ESPAÑA, Elisa; DÍEZ RIPOLLÉS, José Luis; PÉREZ JIMÉNEZ, Fátima; BENÍTEZ JIMÉNEZ, María José; CEREZO DOMÍNIGEZ, Ana Isabel, "Evolución de la delincuencia en España. Análisis longitudinal con encuestas de victimización", en Revista Española de Investigación Criminológica: REIC, $\mathrm{n}^{\circ} 8$ (2010), pp. 1-27, en https://reic.criminologia.net/index.php/journal/article/view/52/49 [visitado el 25/7/2018].

GARCÍA ESPAÑA, Elisa; DÍEZ RIPOLLÉS, José Luis, Realidad y política penitenciarias, Ed. Tirant Lo Blanch, Madrid, 2012.

GARCÍA MAGNA, Deborah, La lógica de la seguridad en la gestión de la delincuencia, Marcial Pons, Madrid, 2018.

GARCÍA MAGNA, Deborah; CEREZO DOMÍNGUEZ, Ana Isabel, "El tratamiento del blanqueo de capitales por la prensa escrita: análisis descriptivo y valorativo", en Revista Electrónica de Ciencia Penal y Criminología, 13-06 (2011), pp. 1-26, en http://criminet.ugr.es/recpc/13/recpc13-06.pdf [visitado el 20/72018].

GARCÍA RIVAS, Nicolás, "Despenalización de la eutanasia en la Unión Europea: autonomía e interés del paciente", en Revista Penal, no 11 (2003), pp. 15-30.

GARCÍA, Juan; ZALDÍVAR, Flor; ORTEGA, Elena; DE LA FUENTE, Leticia; SAINZ CANTERO, Belén, Diez años de funcionamiento de la Ley Orgánica de responsabilidad penal del menor. Junta de Andalucía, Sevilla, 2012.

GARLAND, David, The Culture of Control. Crime and Social Order in Contemporary Society, The University of Chicago Press, Chicago, 2001.

GONZÁLEZ CUSSAC, José Luis; VALLDECABRES ORTIZ, Isabel, "El Anteproyecto de Ley Orgánica de salud sexual y reproductiva y de la interrupción voluntaria del embarazo", en Revista Xurídica Galega, n 59 (2008), p. 13-28.

GRUPO DE ESTUDIOS DE POLÍTICA CRIMINAL (GEPC), Una alternativa al tratamiento jurídico de la disponibilidad sobre la propia vida, Ed. Tirant Lo Blanch, Madrid, 1991.

GRUPO DE ESTUDIOS DE POLÍTICA CRIMINAL (GEPC), Una alternativa a la actual política criminal sobre drogas, Ed. Tirant Lo Blanch, Madrid, 1991.

GRUPO DE ESTUDIOS DE POLÍTICA CRIMINAL, Una alternativa a algunas previsiones penales utilitarias. Perdón, prescripción, dilaciones indebidas y conformidad procesal, Ed. Tirant lo Blanch y GEPC, Madrid, 2014.

HUSAK, Douglas, Sobrecriminalización. Los límites del Derecho penal, Marcial Pons, Madrid, 2013.

LARRAURI PIJOAN, Elena, Criminología crítica y violencia de género, Trotta, Madrid, 2007.

LARRAURI PIJOAN, Elena, “Antecedentes penales y expulsión de personas inmigrantes”,

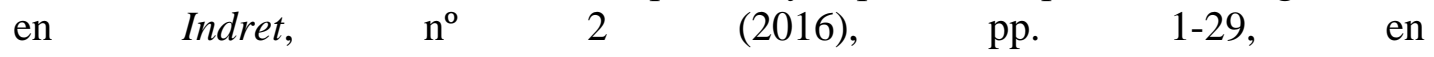
http://www.indret.com/code/getPdf.php?id=1962\&pdf=1214.pdf $\quad$ [visitado el 25/7/2028]. 
GARCÍA MAGNA, Deborah "El recurso excesivo al Derecho Penal en España. Realidad y alternativas".

LAURENZO COPELlO, Patricia, Dogmática y Política Criminal del aborto, Tirant lo Blanch, Valencia, 2012.

LAURENZO COPELLO, Patricia, "Violencia de género y derecho penal de excepción: entre el discurso de la resistencia y el victimismo punitivo", en Cuadernos de Derecho Judicial, 9 (2007), pp. 31-74.

MAQUEDA ABREU, María Luisa, “Es la estrategia penal una solución a la violencia contra las mujeres? Algunas respuestas desde un discurso feminista crítico", en

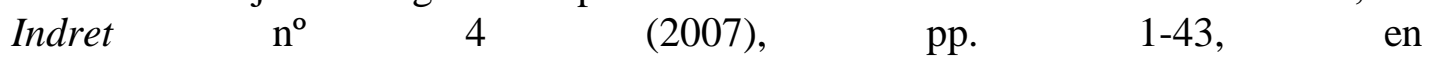
http://www.indret.com/code/getPdf.php?id=1045\&pdf=475_es.pdf [visitado el 20/7/2018].

MARTÍN DIZ, Fernando, La mediación en materia de familia y derecho penal, Ed. Andavira Editora, 2012.

MEDINA ARIZA, Juan José, "Discursos políticos sobre seguridad ciudadana en la historia reciente de España”, en PÉREZ ÁLVAREZ, P. (coord.), Serta: in memoriam Alexandri Baratta, 2004, pp. 1299-1320.

MIRÓ LLINARES, Fernando, “E1 'moderno' Derecho penal vial y la penalización de la conducción sin permiso" en Indret, $\mathrm{n}^{\mathrm{o}} 3$ (2009), pp. 1-54, en http://www.indret.com/code/getPdf.php?id=1284\&pdf=649.pdf [visitado el 25/7/2018].

MUÑOZ SÁNCHEZ, Juan, "La relevancia penal de los clubes sociales de cannabis: Reflexiones sobre la política de cannabis y análisis jurisprudencial", en Revista Electrónica de Ciencia Penal y Criminología, 17-22 (2015), pp. 1-50, en http://criminet.ugr.es/recpc/17/recpc17-22.pdf [visitado el 22/7/2018].

OBSERVATORIO DEL ENTORNO PENITENCIARIO (ROSEP), Informe 2016.

PARLAMENTO EUROPEO, AFET-EUROLAT "Europa y América Latina, la lucha contra la droga y el narcotráfico", 2012.

POZUELO PÉREZ, Laura, La política criminal mediática. Génesis, desarrollo y costes, Marcial Pons, Madrid, 2014.

RANDO CASERMEIRO, Pablo, "La influencia de los grupos de presión en la política criminal de la propiedad intelectual. Aspectos globales y nacionales" en Revista Electrónica de Ciencia Penal y Criminología, 17 (3), (2015), pp. 1-47, en http://criminet.ugr.es/recpc/17/recpc17-03.pdf [visitado el 20/7/2018].

RECHEA ALBEROLA, Cristina; FERNÁNDEZ MOLINA, Esther, Los discursos sobre seguridad ciudadana y lucha contra la delincuencia en la prensa española, Instituto Universitario de Investigación sobre Seguridad Interior, Madrid, 2006.

REY MARTÍNEZ, Fernando, Eutanasia y derechos fundamentales, Centro de Estudios Constitucionales, España, 2008.

ROPERO CARRASCO, Julia, "La insuficiencia del sistema de indicaciones en el delito de aborto" en Anuario de Derecho Penal y Ciencias Penales, Vol. LVI (2003), pp. 211-252.

ROVIRA, Martí; LARRAURI, Elena; ALARCÓN, Pau, "La concesión de permisos penitenciarios", en Revista Electrónica de Ciencia Penal y Criminología, 20-02, (2018), pp. 1-26, en http://criminet.ugr.es/recpc/20/recpc20-02.pdf [visitado el 25/7/2018]. 
RUIZ SIERRA, Joana, "Víctima y mediación penal", en Noticias Jurídicas, 29 de octubre de 2015, en http://noticias.juridicas.com/conocimiento/articulos-doctrinales/10614 victima-y-mediacion-penal/ [visitado el 25/7/2018].

SÁEZ VALCÁRCEL, Ramón, "Juicios rápidos, condenas negociadas, órdenes de alejamiento y deterioro del proceso penal", en Jueces para la Democracia, 49 (2004), pp. 3-8.

SAMUELS, Julie; LA VIGNE, Nancy; TAXY, Samuel, "Stemming the tide: Strategies to reduce the growth and cut the cost of the federal prison system", Urban Institute, nov., $\quad$ pp. 1-62 (2013), eni https://www.urban.org/sites/default/files/publication/24086/412932-Stemming-the Tide-Strategies-to-Reduce-the-Growth-and-Cut-the-Cost-of-the-Federal-Prison System.PDF [visitado el 25/7/2018].

SANZ MULAS, Nieves, Política Criminal. Actualizada a las reformas de 2015, Ratio Legis, 2016.

SILVA SÁNCHEZ, Jesús María, "Los indeseados como enemigos: la exclusión de seres humanos del status personae", en Revista Electrónica de Ciencia Penal y Criminología, no 09-01, (2007), p. 1-18, en http://criminet.ugr.es/recpc/09/recpc09 01.pdf [visitado el 25/7/2018].

STANCU, Oana; VARONA GÓMEZ, Daniel, “¿Punitivismo también judicial? Un estudio a partir de las condenas penales por homicidio en España (2000-2013)", en Revista Electrónica de Ciencia Penal y Criminología, artículo 19-12, (2017), pp. 1-33, en http://criminet.ugr.es/recpc/19/recpc19-12.pdf [visitado el 25/7/2018].

TAMARIT SUMALLA, Josep María, "Sistema de sanciones y política criminal. Un estudio de Derecho comparado europeo", en Revista Electrónica de Ciencia Penal y Criminología, $\mathrm{n}^{\mathrm{o}}$ 9, (2007), pp. 1-40, en http://criminet.ugr.es/recpc/09/recpc09 06.pdf [visitado el 25/7/2018].

VARONA GÓMEZ, Daniel, “Somos los españoles punitivos?: Actitudes punitivas y reforma penal en España", en Indret, $\mathrm{n}^{\mathbf{0}} 1$, (2009), pp. 1-31, en http://www.indret.com/code/getPdf.php?id=1193\&pdf=599.pdf $\quad$ [visitado el 20/7/2018].

VARONA GÓMEZ, Daniel, "Medios de comunicación y punitivismo", Indret, $\mathrm{n}^{\mathbf{o}} 1$, (2011), $\quad$ pp. 1-35, en http://www.indret.com/code/getPdf.php?id=1428\&pdf=791_1.pdf $\quad$ [visitado el 25/7/2018]. 